\title{
Oro y política. Alianzas comerciales y centros de poder en el Bronce Final del Occidente peninsular
}

\author{
Marisa Ruiz-Gálvez Priego*
}

En un reciente artículo (M. Ruiz-Gálvez Priego, en prensa), planteaba la posiblidad de que algunas piezas de orfebreria del Bronce Final, como los torques tipo "Sagrajas-Berzocana", pudieran haber sido regalos politicos que, en un momento como el de los inicios del Bronce Final, cuando la demanda de materia prima y especialmente de Cu y $\mathrm{Sn}$ había crecido grandemente en toda la Europa Centro-occidental, habían contribuido a la inclusión de la Península en esa red de contactos comerciales. La idea sin embargo, por razones de limitación de espacio, no quedó suficientemente argumentada y justificada, como Gonzalo Ruiz Zapatero muy acertadamente me criticó tras la lectura del original.

Quiero pues aprovechar la invitación a participar en el homenaje al profesor Ripoll con motivo de su jubilación, que gentilmente se me ha hecho, para aclarar y apuntalar más sólidamente mis ideas.

El Dr. Ruiz Zapatero argumentaba que no parecía lógico que, en una región donde el oro no escaseaba precisamente, y que por lo tanto no podría haber sido en ningún caso considerado como materia prima exótica, objetos fabricados en ese metal hubieran sido utilizados como don introductorio a unas relaciones comerciales, y que nada probaba que no hubieran podido ser más bien obtenidos en calidad de tributo, recaudado dentro del propio territorio en lugar de importados de otros lugares.

\footnotetext{
* Universidad de Alcalá de Henares.
} 
A ello, me atrevo a contraponer una serie de argumentos que trataré de ir desarrollando en estas páginas:

\section{EL MODELO DE LA POLÍTICA DE REGALOS}

Basado en el ensayo de Marcel Mauss sobre el Don, según el cual hacer una donación es donarse a uno mismo, de tal modo que si el regalo es aceptado, se establece una relación social entre donante y receptor (M. Mauss, 1923-24; C. Mac Cormack 1981: 161), el modelo insiste en el hecho de que, en las sociedades primitivas, por el intercambio de regalos el donante alcanza prestigio y consideración social (C. Haselgrove, 1982; C. Renfrew, 1986). Algo que el saber popular español es capaz de expresar muy gráficamente en el refrán: “Dar es señorio; recibir es servidumbre"... Es decir, el acto de donación confiere superioridad social al donante. La donación sin contradonación, acarrea una situación de dependencia para el receptor hasta tanto no tenga lugar un gesto recíproco de mayor o al menos, de valor equivalente al don recibido. Aún en nuestros días, ninguna visita de Estado se inicia sin el preceptivo intercambio de regalos entre los jefes de gobierno, que más allá del gesto de cortesía, refleja el deseo por ambas partes de obligarse mutuamente por la deuda de amistad y gratitud, tras del que se esconde el más prosaico, de hacer negocios y obtener beneficios. Morris ha argumentado recientemente que, en la Grecia arcáica, donde se conservaban aún en la naciente sociedad estatal rasgos propios de una sociedad clánica, la política de regalos seguía siendo el mecanismo a través del cual se realizaban los intercambios intercomunales, partiendo del establecimiento de una vinculación personal por la ofrenda de regalos y hospitalidad, que permitían la circulación comercial dentro de un contexto de mutua dependencia (I. Morris, 1986: 5).

El modelo de los regalos políticos, se ha usado por parte de diversos autores para explicar el surgimiento de las sociedades de tipo "Jefatura", de la Primera Edad del Hierro en Centroeuropa (M. Frankestein, S. Rowlands, 1978; P. van der Velde, 1985; P. S. Wells, 1980, 1984 y 1985) y en la sociedad de Campos de Urnas del Hierro del Noreste de la Península Ibérica (G. Ruiz Zapatero, 1983-84). De acuerdo con este modelo, es el comercio externo (el etrusco y griego en el caso de Centroeuropa; el fenicio y posteriormente, el griego, en el de la Península lbérica) el detonante de la diferenciación social y de la aparición de individuos ca- 
paces de reorganizar la producción, a fin de obtener excedentes con los que adquirir los objetos de lujo llegados por comercio, y reforzar por su intermedio, su posición en el seno de sus propias comunidades.

Al crecer la productividad de su sistema económico, aumentan también la riqueza y el poder de las cabezas de la comunidad, y ésta aunque no se beneficie por lo general del acceso al comercio de bienes de lujo, si lo hace del aumento de tamaño de la misma y de la existencia de excedentes. Una red de jefes y subjefes de distintas categorías, de acuerdo a su cercania en los vínculos de parentesco con el jefe supremo, canalizan hacia éste dichos excedentes en forma de tributo, y su fidelidad se ve recompensada y "comprada" por la recepción en forma de Don, de algunos de los objetos de lujo procedentes del comercio externo, y que el jefe supremo redistribuye entre sus vasallos conforme a la categoría de éstos y sus vínculos de parentesco, para afianzar su poder y asegurarse su sumisión.

\section{NATURALEZA DE LOS REGALOS POLÍTICOS}

Para entender plenamente este sistema, hay que tener en cuenta que el objetivo del comercio primitivo no es como para nosotros, la exportación de productos sino bien por el contrario, la importación, en especial de objetos lejanos y apreciados o de materias primas y técnicas exóticas o novedosas (G. Dalton, 1975).

Y ello es así, porque la posesión de objetos lejanos y exóticos concede a su posesor, como vimos más arriba, un prestigio que abre la puerta a otros recursos vedados a quienes carecen de él, recursos de valor ahora económico y no sólo social o simbólico, y cuya posesión representa por tanto, riqueza y poder (C. Renfrew, 1986: 161).

Así Dalton y siguiendo a este autor, Colin Renfrew, habla de "objetos de valor primario", en contraposición a aquellos de uso diario. Los primeros serían aquellos objetos especialmente preciados por su valor simbólico y generalmente, por su escaso o nulo valor práctico, frente a los objetos de uso diario que circulan libremente en los mercados de intercambio. Ambas categorías circulan en esferas diferentes y no son intercambiables entre sí, como en el caso del comercio kula (G. Dalton, 1977; C. Renfrew, 1986). Estos objetos de valor primario son generalmente apreciados por su capacidad de atraer nuestros sentidos, especialmente 
la vista, en el caso de los metales brillantes o de las piedras traslúcidas; pero también el tacto, como las conchas o las pieles, o nuestro olfato y gusto, como las sustancias aromáticas o el vino, levemente embriagadores y que actúan por tanto en conjunto sobre todos ellos, excitándolos (C. Renfrew, 1986).

Pero el valor de estas materias como objetos conferidores de prestigio para su poseedor pudo ser cambiante. En el momento en que la cantidad de este aumenta y se hace más accesible a un mayor número de personas, o en que la aparición de una nueva materia exótica la desplaza, pierde su valor primario para adquirir un valor económico, como ocurre con el ámbar, desplazado de las tumbas del Norte de Europa por el metal como elemento de prestigio, o como ocurre en Centroeuropa durante la Edad del Hierro con el coral del Mediterráneo (S. Shennan, 1982; S. Champion, 1982 y 1985).

En esos momentos es la cantidad de materia prima acumulada más que su calidad, la que confiere prestigio y riqueza (C. Renfrew, 1986: 162).

\section{LO QUE ARQUEOLÓGICAMENTE NOS PERMITE HABLAR DE IMPORTACIÓN}

Tratemos en primer lugar de aclarar nuestras ideas acerca de aquello que consideramos importación, imitación o transformación de modelos o técnicas originariamente importados.

En un reciente artículo, Deborah Olausson propone cinco argumentos que, en su opinión, permiten identificar como importados ciertos objetos:

1. Identificación espacial de las materias primas extraídas en lugar objeto de estudio.

2. Identificación de los elementos estilísticos o de las técnicas que difieren de las otras de la misma clase de objetos en un sitio dado. 
Oro y política. Alianzas comerciales y centros de poder en el bronce

3. Dos objetos que aparecen en diferentes contextos en dos sitios.

4. Ausencia de precedentes locales para un tipo dado.

5. Distribución espacial limitada (Olausson, D., 1988: 15).

En el caso de los torques "Sagrajas-Berzocana", el oro empleado en su confección de acuerdo con los análisis de Axel Hartmann, corresponde a los grupos " $\mathrm{M}$ ", " $\mathrm{N}$ » y derivados, oros aleados, con cobre principalmente, cuyos tanto por ciento de este metal son similares a los centroeuropeos, punto de origen en su opinión, de este tipo de oro, si bien es cierto que el criterio en que se basa Hartmann para considerar o no de origen peninsular un tipo de oro ha sido básicamente el empleo de mapas de dispersión, que no son ni mucho menos argumento definitivo (Hartmann, A., 1979 y 1981). No hay que descartar por tanto de modo taxativo que, en una región como aquella en la que aparecen los torques "Sagrajas-Berzocana", donde el oro no escasea y fue explotado desde la Prehistoria, su fabricación pudiera haber sido local. Los criterios $2 .^{\circ}$ y $4 .^{\circ}$ si nos ofrecen una mayor base a nuestros argumentos. Como Almagro Gorbea, quien estudió y tipificó esta clase de orfebrería indicaba, aspectos técnicos, como el sistema de cierre a base de dos piezas unidas por machihembrado del torques de Sagrajas, así como de tipo estilístico, tienen sus mejores paralelos en la orfebrería atlántica, especialmente la bretona, de fines del Bronce Medio y sobre todo, del Bronce Final y carecen de precedentes locales en nuestro suelo (M. Almagro Gorbea, 1974 y 1977: 18 y ss.). La ya mencionada autora sueca señala a este respecto, que el criterio tecnológico más que el estilistico es probablemente el mejor indicador de importación de objetos o de movimiento de artesanos, porque el segundo puede ser el resultado de simple copia o de fenómenos de convergencia (D. Olausson, 1988: 17).

La distribución de estos torques, criterio $5 .^{\circ}$ de Olausson es ciertamente limitada, pues aparte el occidente de la Península Ibérica piezas similares sólo se conocen en el occidente francés (Ch. Eluère, 1982) y sur de Inglaterra y llamo la atención sobre el hecho de que empleo la palabra similar y no igual, porque salvo tal vez el torques de la región del Marne conservado en el Metropolitam Museum de Nueva York (Ch. Eluère, 1982: fig. 91), los torques ingleses y franceses son "primos" pero no «hermanos» de los españoles. 
En cuanto al último criterio propuesto por Olausson, los contextos de aparición (criterio $3 .^{\circ}$ ), la casi nula información sobre cómo se produjeron en uno y otro caso los hallazgos, anula toda posibilidad de hacer uso de este criterio.

Sin embargo nos cuesta aceptar que estas piezas pudieran ser importaciones, tal vez porque estamos acostumbrados a asociar la idea de importación, con la llegada "masiva" de productos ligada a las colonizaciones históricas. Debemos considerar sin embargo que estamos tratando con objetos que por su exclusividad tuvieron que llegar en escaso número en su propia época. $Y$ si tenemos además en cuenta que los testimonios arqueológicos de la existencia de una cultura que alcanzan a llegar a nuestras manos, suponen apenas una minima y a veces, parcial parte del conjunto constitutivo de la misma, comprenderemos que nuestras probabilidades de recuperar una auténtica pieza importada con anterioridad a la llegada de productos fabricados «en serie» para la exportación, como se produce con el comercio fenicio, son bastante escasas, y ello sin embargo no significa necesariamente que tales importaciones no existieran. Si los torques "Sagrajas-Berzocana" que conocemos se fabricaron localmente, en todo caso lo hicieron a partir de modelos importados.

De no contar con el testimonio grabado en las estelas del SO., ignorariamos la existencia, presumiblemente importados, de escudos, espejos, liras y carros a fines de la Edad del Bronce, de los que no se conocen ejemplares reales, pero que el artista indígena tuvo necesariamente que ver para copiar. Tampoco somos capaces en la mayoría de los casos, de reconocer importaciones entre las espadas del Bronce Final, y sin embargo resulta impensable que, en cada región y de modo independiente pero coetáneo, llegaran a las mismas soluciones técnicas y estilísticas.

Si pensamos que una dominación tan breve como la británica sobre la isla de Menorca durante el siglo XVIII, ha dejado improntas perdurables en su arquitectura, y hasta en sus costumbres, nos daremos cuenta de que no son precisos unos contactos muy prolongados ni un flujo masivo de productos para dejar huella en el seno de una comunidad humana. Por ello, a menudo tendremos que limitarnos a inferir a partir de evidencias indirectas, que ciertos procesos tuvieron lugar, o que determinados objetos debieron existir, aunque carezcamos de pruebas tangibles de que ello fuera así en realidad.

Otros criterios para diferenciar importaciones, imitaciones y adaptaciones, son los propuestos por Thrane: 
1. Si todos, o la mayoría de los elementos tipológicos de un objeto son de origen local, los objetos son probablemente locales.

2. $\mathrm{Si}$ algunos son relacionables con tipos foráneos, el objeto probablemente refleja influencias externas.

$3^{\circ}$ Si todos o la mayoría de sus elementos tipológicos son foráneos, el objeto es probablemente importado.

$4 .^{\circ}$ Si alguno de sus elementos, como la decoración son locales, puede ser copia de un objeto foráneo $(H$. Thrane, 1975; $D$. Olausson, 1988: 16).

Si estos criterios los aplicamos no individualmente a cada uno de los torques, sino en conjunto a la orfebrería "Sagrajas-Berzocana», los que mejor se amoldan a sus características son el $2 .^{\circ}$ y el $3 .^{\circ}$, pues forma, decoración y sistema de cierren carecen de precedentes en la Península, y si por el contrario los poseen fuera, amén de haber paralelos para estos torques fuera de la Península. Por el contrario, el primitivo sistema de soldadura de ejemplares como los de Sagrajas o Sintra, no tiene por qué reflejar necesariamente innovaciones técnicas llegadas de fuera, sino que muy probablemente pudieron adquirirse como consecuencia de los paulatinos avances técnicos en la propia metalurgia local del bronce.

De otra parte, variante dobles o triples de los torques "SagrajasBerzocana", no se conocen fuera de la Península lbérica, si bien es cierto que en el mundo del Bronce Nórdico se conocen los Halskragen, aunque carecemos de indicios que avalen otra relación entre éstos y los peninsulares, que la simple convergencia, por lo que cabe pensar que esta variable se pudo haber originado aquí. Asimismo, aspectos técnicos de la decoración parecen marcar diferencias entre los ejemplares ibéricos y los restantes ${ }^{1}$. Por todo ello, me inclino a pensar que los torques y brazaletes que han llegado a nuestras manos pueden ser adaptaciones de objetos foráneos llegados como "regalos políticos", e incorporados al lenguaje simbólico del poder de las élites indígenas.

' Comunicación oral de Alicia Perea, quién prepara su Tésis Doctoral sobre aspectos técnicos de la orfebreria prehistórica y ha tenido ocasión de estudiar estos torques desde tal pespectiva. 


\section{LOS TORQUES COMO REGALO POLÍTICO}

Durante gran parte del Bronce Pleno, la Península parece desconectada del comercio atlántico. Las razones de ello, ya expuestas en otro lugar (Ruiz-Gálvez, M. Priego, 1984, 1984a y 1987), parecen radicar en la puesta en explotación de otras áreas productoras de cobre, un cambio en el flujo de la demanda, incrementada ahora en las zonas de contacto entre el mundo centroeuropeo y el occidental, y la aparición de regiones mejor situadas estratégicamente para canalizar ese flujo, que desplazan y postergan a la Península, excesivamente alejada del tráfico comercial entre Centroeuropa y Occidente. Ello es palpable en la escasez y claro aspecto local de la metalurgia de esta época en el occidente peninsular.

A partir de inicios del Bronce Final, se produce un acentuado aumento de la demanda de metal atlántico reflejado no solamente por la mayor producción ahora de objetos metálicos, sino igualmente y como señalan los análisis, por la preferencia del metal de este origen sobre el centroeuropeo (P. Northover, 2982; R. Bradley, 1988). Las causas de este aumento, igualmente expuestas con anterioridad (Ruiz-Gálvez, M. Priego: 1987, en prensa), están estrechamente ligadas a la expansión de los $\mathrm{Cu}$ hacia Europa occidental y a la aplicación de la metalugia a la obtención de armas e instrumentos más eficaces, para defender y rentabilizar los campos. Es sólo ahora, cuando comienza a compensar el esfuerzo de ampliar las redes comerciales hacia lugares más alejados como la Península Ibérica, y cuando ciertas regiones estratégicas situadas, comienzan a articular el comercio de metal en la Peninsula (Ruiz-Gálvez, M. Priego: 1986). Es en este momento cuando nuevos tipos de armas, espadas y útiles comienzan a alcanzar Iberia, probablemente en un deseo de incentivar la explotación del mineral local más, que meramente de comerciar con unos productos.

Cabe pensar que por el valor simbólico e ideológico de espadas y joyas, estas circularan en esferas distintas de los útiles, y que junto a ellos, circularan otras materias perecederas, desde sal a tal vez, seres humanos. A cambio de ello, y junto a otras posibles mercancías valiosas y perecederas, lo que se obtenía era mineral, tanto para el consumo de los propios talleres atlánticos como para cubrir la demanda centroeuropea.

Pero la introducción de estos nuevos tipos, aunque vienen a sustituir por su mayor perfección a los fabricados localmente, no implica el empleo de técnicas complejas o sofisticadas, fuera por tanto del alcance de 


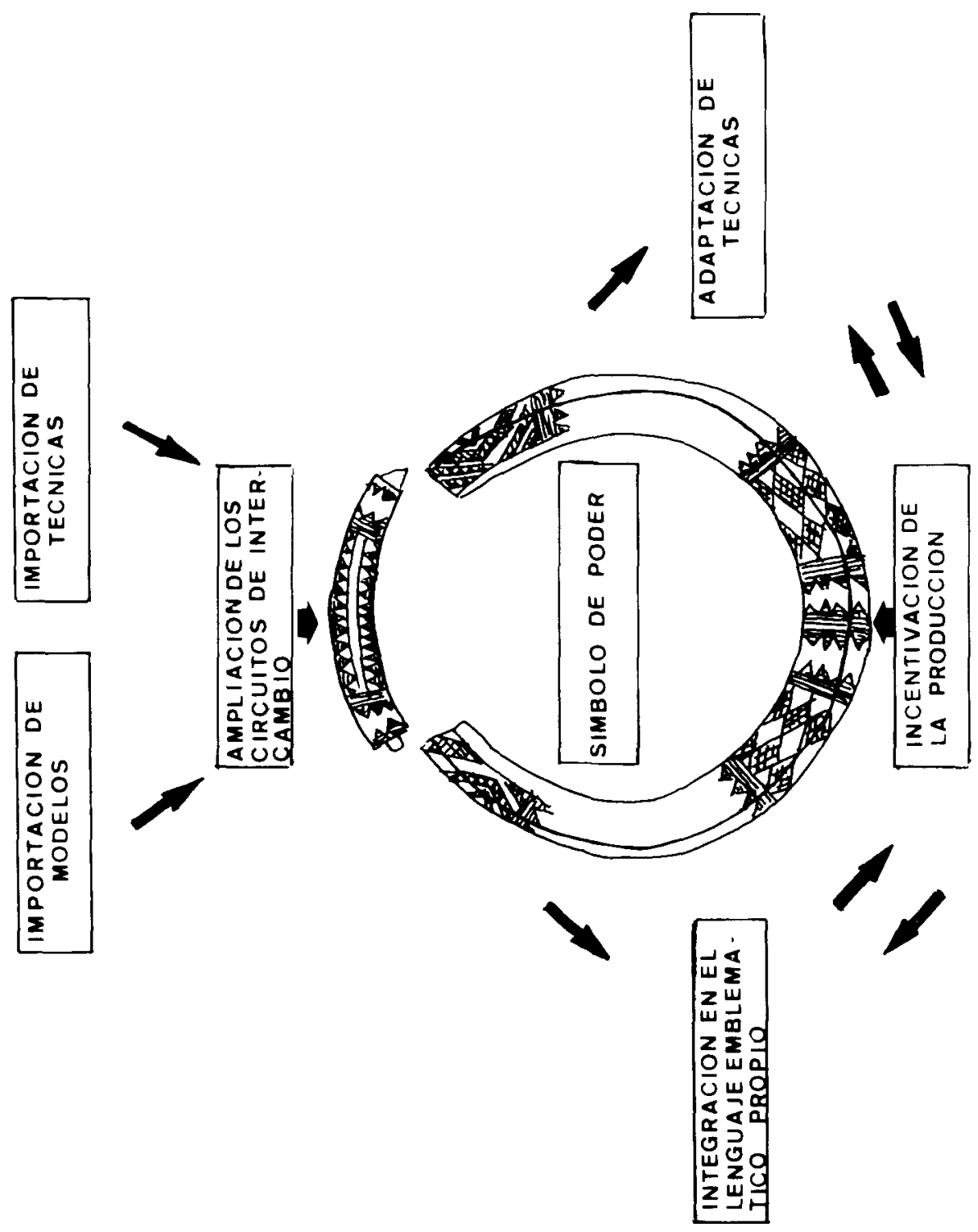


un metalúrgico o de un orfebre de la Edad del Bronce, como sí lo fueron el uso de filigrana y granulado, el manejo del torno, la soldadura o el propio manejo del hierro, cuyo empleo implica el aprendizaje de unos procedimientos técnológicos totalmente fuera del alcance de los que el "europeo" de la Edad de Bronce pudiera adquirir por si mismo mediante la práctica, y que hicieron por mucho tiempo insuperables y dificilmente imitables, las importaciones mediterráneas del primer Milenio a. C.

Ello quiere decir que estas piezas, pudieron rápidamente ser adaptadas al abanico de producciones metalúrgicas locales y al lenguaje emblemático del poder, en tanto que las torpes imitaciones de cráteras griegas que conocemos en contextos ibéricos, reflejan las dificultades con las que, siglos más tarde, topan los artesanos indígenas para asimilar una tecnologia nueva, superior y totalmente ajena a la que formaba parte hasta el momento, de su propio bagaje de aprendizaje y experiencia, hecho que justifica también el lapso de tiempo transcurrido desde la introducción a la plena generalización del uso del hierro entre los indígenas. Por ello, dentro y fuera de la Península, en el amplio conglomerado de objetos metálicos de la Edad del Bronce, es tan difícil identificar importaciones. Todo parece indicar por el contrario, una rápida aceptación de producciones que con presteza, son traducidas al gusto local y fabricadas regionalmente en el marco de un mercado dinámico, donde objetos emblemáticos o de prestigio como cascos, espadas, escudos, asadores, calderos, ganchos de trinchar carne... etc, se innovan y suceden con gran celeridad, mientras que hachas, escoplos, o cinceles, se producen masivamente sin apenas variar a lo largo del tiempo.

Es muy posible entonces que estos torques, que llegaron a la Peninsula a inicios del Bronce Final desde otras áreas atlánticas, tal vez desde Francia donde sus más cercanos paralelos se sitúan a fines del Bronce Medio/inicios del Bronce Final, como regalos políticos que permitieran establecer vínculos de amistad e incorporar el Occidente Peninsular al mercado atlántico, fueran incorporados y adaptados al gusto indígena y fabricados localmente. Su valor emblemático derivaria paulatinamente en el transcurso del final de la Edad de Bronce, no del caracter más o menos exótico del modelo o de la técnica de fabricación, sino del empleo en su factura de una gran cantidad de una materia prima, que se vuelve cada vez más escasa y apreciada.

Ciertamente, ningún torques macizo británico o francés alcanza el peso en oro de los ejemplares ibéricos, algunos de los cuales como el de Evora de un aro o el de Sagrajas, de dos aros soldados, llegan a pesar más de los $2 \mathrm{~kg}$., mientras que el de Penela de un aro, se acerca a los $2 \mathrm{~kg}$. y el de Sintra de tres, pasa bastante más del kilo de oro. Y 
es esa capacidad de atesorar una materia prima costosa y cada vez más rara en Occidente, donde Christiane Eluére atribuye los altísimos porcentajes de cobre y plata en los oros británicos y franceses, mucho mayor que en los oros danubianos e ibéricos, a una creciente carestía de este metal, que les afectó desde aproximadamente el 1.000 a.C., y que incidió tal vez menos o más tardiamente en estas dos últimas regiones (Chr. Eluére 1987: 81 a 83) lo que confiere ahora a estos torques su valor como objetos de prestigio, y a quién controle ese territorio, un enorme poder.

Esta carestía debió sentirse también finalmente en el Occidente de la Península Ibérica, pues torques como los del tesoro de Alamo, con piezas de uno y tres aros, similares a los de "Sagrajas-Berzocana", pero huecos y más modernos, por la presencia ya de hilos soldados, presentan pesos muy inferiores, de $171 \mathrm{gr}$. para el torques simple y 732,8 gr, para el formado por tres aros ( $E$. Jalhay, 1931) y porque durante la Edad del Hierro, los torques castreños son de oro bajo (A. Hartmann, 1982).

Si estos torques fueron piezas de uso femenino como quiere Almagro Gorbea (M. Almagro Gorbea, 1977 y en prensa), o si a partir de su fabricación local circularon como tributo y como monopolio de individuos de alto rango (1. Morris, 1986: 9; C. Godsen, 1986) y cuál fue la verdadera raiz en que radicaba el poder, si en el control del comercio de mineral o en el control de la tierra y la producción, al estilo de la polémica Rowlands/Godsen sobre el origen de las Jefaturas de la Primera Edad del Hierro (Frankestein/Rowlands 1978; C. Godsen, 1985; Rowlands/Godsen/Bradley 1986), son preguntas que sobrepasan con creces la información de que disponemos pero que deben quedar planteadas.

Sí quiero señalar al menos, que torques como estos, o como los de Bodonal de la Sierra, a los que podría aplicarse idéntica explicación, delatan la existencia desde fines de la Edad del Bronce, de una creciente concentración del poder ${ }^{2}$.

Madrid, enero de 1989.

${ }^{2}$ Este texto se ha visto corregido y enriquecido con los comentarios, críticas y aportaciones de Martín Almagro Gorbea, Alicia Perea, Juan Pereira y Gonzalo Ruiz Zapatero. Los posibles errores y equivocaciones son de mi única responsabilidad. 


\section{BIBLIOGRAFÍA}

Almagro Gorbea, M., 1974: Los tesoros de Sagrajas y Berzocana y los torques de oro macizo del Occidente Peninsular. Actas del III. ${ }^{\text {er }}$ Congreso Nacional de Arqueología, Porto.

- 1977: El Bronce Final y el Período Orientalizante en Extremadura. Bibliotheca Praehistorica Hispana XIV.

- Las estelas antropomorfas en la Península Ibérica. Tipología, dispersión, cronologia y significado. (En prensa).

BRADLEY, R., 1988: Hoarding, recycling and the consumption of prehistoric metalwork: technological change in western Europe. World Archaeology, vol. 20, n. ${ }^{\circ} 2$.

CHAMPION, S., 1982: Exchange and ranking: the case of coral. En C. Renfrew y S. Schennan (eds.): Ranking, resource and Exchange. Aspects of the Archaeology of early european society, Cambridge University Press.

- 1985: Production and exchange in Early Iron Age Central Europe. En T. C. Champion y J. V. L. Megaw (eds.): Settlement and society. Aspects of west european Prehistory in the first millenium B. C., Leicester University Press.

Dalton, G., 1975: Karl Polany'x analysis of long-distance trade and his wider paradigm. En J. Sabloff y C. Lamberg-Karlowsky (eds.): Ancient civilisation and trade, Alburquerque, Univ. of New Mexico.

- 1977: Aboriginal economies in stateless societies. En T. Earle y J. E. Ericson (eds.): Exchange systems in Prehistory, Nueva York, Academic Press.

Eluére, CH., 1982: Les ors préhistoriques. Paris, ed. Picard.

- 1987: L'or des celtes. Paris, L'Office du livre.

FRANKESTEIN, S. y RowLANDS, M., 1978: Early Iron Age society in south west Germany. Inst. Archaeol. Bull. 15.

Godsen, CH., 1985: Gifts and kin in Early Iron Age Europe. MAN n. ${ }^{\circ} 20$, 3. 
HARTMANN, A., 1979: Irish and british gold types and their west european counterparts. En M. Ryan (ed.): Proceedings of the fifth Atlantic colloquium, Dublin.

- 1982: Prähistorische Goldfunde aus Europa II. Studien Zu den Anfängen der Metallurgie, Band n. ${ }^{\circ} 5$, Berlín, Gebr. Mann.

HASELGROVE, C., 1982: Wealth, prestige and power: The dynamics of late iron age political centralisation in south-east England. En C. Renfrew y S. Shennan (eds.): Ranking resource and exchange. Aspects of the Archaelogy of the early european society, Cambridge University Press.

Jalhay, E., 1931: O tesouro do Alamo (Moura, Alentejo). Lisboa. C. Maccormack.

- 1981: Exchange and hierarchy. En A. Sheridan y F. Bailey (eds.): Economic Archaeology, British Archaeological Repport, International Series n. ${ }^{\circ} 96$.

Mauss, M., 1950: Essai sur le don. Forme et raison de L'échange dans les societés archaiques. L'Année Sociologique. También recopilado en: M. Mauss: Sociologie et Anthropologie, Paris, P.U.F., 1923-24.

MorRIS, I., 1986: Grift and commodity in archaic Greece. MAN n. 21.

NoRTHOVER, P., 1982: The exploration of the long-distance movement of bronze in Bronze and Early Iron Age Europe. Bull. Inst. Arch. Univ. London, $\mathrm{n}^{\circ} 19$.

OlAUSSON, D., 1988: Dots on a map.-Thoughts about the way archaeologist study prehistoric trade and exchange. En B. Hårdh, L. Larsson, D. Olausson y R. Petré (eds.): Trade and exchange in Prehistory Studies in honour of Berta Stiernquist. Lunds Universitets Historiska Museum.

RENFREW, C., 1986: Varna and the emergence of wealth in prehistoric Europe. En A. Appadurai (ed.): The social life of thigns. Commodities in cultural perspective. Cambridge University Press.

Rowlands, M., Godsen, C. y Bradley, R., 1986: Modernist fantasies in prehistorty? MAN n. ${ }^{\circ} 21$.

Ruiz-Galvez Priego, M., 1984: La Península lbérica y sus relaciones con el círculo cultural atlántico. Madrid, Servicio de Reprografía de la Universidad Complutense.

- 1984a: Cuestiones terminológicas acerca de la Edad del Bronce Peninsular. Trabajos de Prehistoria $\mathrm{n}^{\circ} 41$.

- 1986: Navegación y comercio entre el Atlántico y el Mediterráneo a fines de la Edad del Bronce. Trabajos de Prehistoria n. ${ }^{\circ} 43$.

- 1987: Bronce Atlántico y "cultura" del Bronce Atlántico en la Península Ibérica. Trabajos de Prehistoria n. ${ }^{\circ} 44$. 
- La orfebrería del Bronce Final: El poder y su ostentación. Revista de Arqueologia. n. ${ }^{\circ}$ monográfico (en prensa).

Ruiz Zapatero, G., 1983-84: El comercio protocolonial y los orígenes de la iberización. Dos casos de estudio, el Bajo Aragón y la Cataluña interior. Kalathos n. ${ }^{\circ}$ 3-4.

SHENNAN, S., 1982: Exchange and ranking: the role of amber in the earlier Bronze Age Europe. En C. Renfrew y S. Shennan (eds.); Ranking, resource and exchange. Aspects of the Archaeology of early european society, Cambridge University Press.

ThrANe, H., 1975: Europaeiske forbindelser. Copenhague, Van der P. Velde.

- 1985: Early State formation in Iron Age Central Europe. En H. J. M. Claessen/P. van der Velde y M. E. Smith (eds.): Development and decline: The evolution of sociopolitical organitation, South Hadley, Bergin \& Hadley.

WELL, P. S., 1980: Culture contact and culture change. Early Iron Age Central Europe and the Mediterranean world. Cambridge University Press.

- 1984: Farms, villages and cities. Commerce and urban origins in Late prehistoric Europe. Cornell University Press.

- 1985: Mediterranean trade and culture change in Early Iron Age Central Europe. En T. C. Champion y J. V. S. Megaw (eds.): Settlement and society: Aspects of Western european prehistory in the first millenium $B C$, Leicester University Press. 